\title{
EDUCAÇÃO ESPECIAL NO ENSINO SUPERIOR: CONTRIBUIÇÕES E PERSPECTIVAS
}

\author{
Doracina Aparecida de Castro ARAUJO ${ }^{1}$ \\ Carla Cristina Castro ARAUJO ${ }^{2}$ \\ Elson Luiz de ARAUJO ${ }^{3}$
}

Resumo: Com o advento da Educação Especial no Brasil impulsionado pela Declaração de Salamanca (1994), algumas posições teóricas se apresentaram, a exemplo da inclusão total das pessoas com deficiência nas escolas comuns e da inclusão a partir do olhar da perspectiva do desenvolvimento das funções psíquicas superiores (VIGOTSKI, 1997). Para além, há outras posições teóricas e práticas educativas intermediárias voltadas às condições orgânicas dos alunos com deficiência e às possibilidades de inserção daqueles mais comprometidos em relação à deficiência, em centros de educação especializados. A partir dessas considerações é que se objetiva compreender as contribuições dos autores de 12 artigos da Revista Brasileira de Educação Especial (RBEE) sobre Educação Especial no Ensino Superior, assim como as perspectivas para o discente Público-Alvo da Educação Especial (PAEE) que ingressa no Ensino Superior. A abordagem qualitativa, sob a perspectiva da Psicologia Histórico-Cultural, norteou a análise dessas produções da RBEE, no período de 2010 a 2014. Como resultado verificou-se que os discentes PAEE que chegam ao Ensino Superior enfrentam dificuldades suscitadas por meio de preconceito velado, acessibilidade física, inadequação curricular, entre outras. Pode concluir-se que a inclusão de alunos PAEE carece de atenção, desde a Educação Infantil, com a realização de trabalhos educacionais pautados no desenvolvimento de suas funções psíquicas superiores, para que consigam transpor as barreiras localizadas em todos os níveis de escolarização, de modo a contribuir para que não só cheguem ao Ensino Superior, mas também (e sobretudo) que saiam com conhecimento.

Palavras-chave: Educação especial. Ensino superior. Produção intelectual. Psicologia Histórico-Cultural.

\section{INTRODUÇÃO}

A Educação Especial, a partir da Declaração de Salamanca, aprovada em 1994, tomou novos rumos no Brasil, mesmo com o enfrentamento de duas tendências opostas, marcadas por constantes embates, que influenciam a definição das políticas públicas para o Público-Alvo da Educação Especial (PAEE), em todos os níveis de

\footnotetext{
${ }^{1}$ Educação. UEMS - Unidade Universitária de Paranaíba. Paranaíba - MS - Brasil. 79500-000 doracina@uems.br.

${ }^{2}$ Psicologia. IPECS - Instituto de Psicologia, Educação, Comportamento e Saúde de São José do Rio Preto. São José do Rio Preto - SP - Brasil. 15015-800 - psicarlacastro@ hotmail.com.

3 Educação. UEMS - Unidade Universitária de Paranaíba. Paranaíba - MS - Brasil. 79500-000 elsonla@uems.br.
} 
escolarização. Por um lado, está a defesa da inclusão total do PAEE nas escolas comuns e, por outro lado, os que defendem a inclusão apenas para quem oferece condições orgânicas, mesmo que poucas, para aprender. Nesse debate, também aparecem as contribuições do texto da defectologia, conforme estudos de Vygotski (1997), que defende que todos podem desenvolver suas funções psíquicas superiores, dependendo do trabalho por meio de mediações e compensações sociais e da observação constante às habilidades e potencialidades de cada um, trabalhando com a utilização da adaptação curricular.

Para contribuir com esses debates, várias pesquisas foram realizadas no País, em diferentes locais e tempos. No entanto, muitos trabalhos permanecem guardados nas bibliotecas das universidades, ou são pouco divulgados em eventos científicos, ou até mesmo esquecidos pelo tempo de publicação. Assim, este artigo se propõe a divulgálas, partindo de uma análise voltada para a compreensão das contribuições suscitadas pelos pesquisadores, cujos estudos centram-se nos sujeitos PAEE, que ingressam no Ensino Superior, além de verificar as perspectivas da Educação Especial no Ensino Superior.

Para atingir o objetivo proposto, algumas questões foram levantadas, a saber: as contribuições dos autores dos artigos da Revista Brasileira de Educação Especial (RBEE) para o Ensino Superior, no período de 2010 a 2014 condizem com as necessidades do PAEE? Os temas publicados pelos autores dos artigos da RBEE sobre Ensino Superior, no período de 2010 a 2014, indicam prevalência para qual PAEE? As revelações dos autores da RBEE sobre o tema Educação Especial no período de 2010 a 2014 contribuem para a práxis dos docentes do Ensino Superior? É possível identificar uma tendência teórica nos artigos que associam Educação Especial e Ensino Superior?

Com as questões de estudos levantadas e o objetivo definido, buscamos na abordagem qualitativa, a partir dos contributos teóricos da Psicologia HistóricoCultural, compreender as produções intelectuais da RBEE, sobre Educação Especial no Ensino Superior, no período de 2010 a 2014, por meio da análise de 12 artigos ${ }^{4}$ cujo foco corresponde ao objeto do estudo - produções intelectuais de pesquisadores do Brasil que publicaram nesse periódico. É importante considerar que a RBEE tem uma

\footnotetext{
${ }^{4}$ Os artigos analisados constantes nas tabelas 1, 2, 3, 4 e 5 não figurarão nas referências bibliográficas, mas sim a Revista Brasileira de Educação Especial (2015), que publicou os mesmos, em seus respectivos anos de publicação.
} 
vasta história de contribuições à área de Educação, em especial à subárea Educação Especial.

Para a descrição do trabalho desenvolvido e apresentação dos resultados obtidos, organizamos o texto em um único tópico abrangente "Revista Brasileira de Educação Especial: contribuições e perspectivas para a Educação Especial no Ensino Superior”. Nas considerações finais, buscamos retomar as questões de estudo, com o fito de refletir sobre o escopo da pesquisa e compreender as contribuições vindas de diversos autores, relevantes e compatíveis com o tema, assim como as perspectivas dos discentes no Ensino Superior.

\section{Revista Brasileira de Educação Especial: contribuições e perspectivas para a Educação Especial no Ensino Superior}

A Revista Brasileira de Educação Especial (RBEE) teve sua primeira publicação em 1992. Durante a realização do III Seminário Brasileiro de Pesquisa em Educação Especial, em 1993, um grupo de pesquisadores fundou a Associação Brasileira de Pesquisadores em Educação Especial, na cidade do Rio de Janeiro. Essa Associação tinha por objetivo manter ativa a revista e de ter um veículo socializador do trabalho dos professores e dos pesquisadores do Brasil e de outros países para manter o tema Educação Especial como uma área de estudos e desenvolvimento do conhecimento entre pesquisadores iniciantes, experientes e profissionais interessados pela Educação Especial. A partir de 2005, a RBEE tornou-se uma referência, sendo avaliada e incorporada ao SciELO, em seu volume 11, número 2. A Revista publicou (de 1992 a 2014) um total de 52 números. Entre os anos de 2010 a 2014 foram 33 números. Desses 33 números editados pela RBEE, 158 foram realizados em forma de relatos de pesquisas. Em 2010 foram publicados 25 artigos - em formato de relatos de pesquisas pela Revista Brasileira de Educação Especial, mas apenas um tratou do tema Educação Especial no Ensino Superior, conforme Tabela 1.

Siqueira e Santana (2010, p.127), ao apresentar as “[...] propostas de acessibilidade para a inclusão de pessoas com deficiências no ensino superior", destacam pontos importantes para a efetivação da inclusão escolar de pessoas com deficiência no Ensino Superior e alertam sobre a importância da compreensão nesse processo, inclusive das pessoas com deficiência, tendo em conta o reconhecimento de suas fragilidades e habilidades. As autoras concordam com a Classificação Internacional de Funcionalidade, Incapacidade e Saúde (CIF), afirmando que ela nos convida a 
verificar outros aspectos, como os que “[...] estão envolvidos na qualidade de vida das pessoas com deficiência, tirando o foco das alterações das funções e estruturas do corpo e pensando os fatores ambientais e pessoais que influenciam a realização de atividades e participação e permitem a funcionalidade”. (SIQUEIRA; SANTANA, 2010, p.135).

Quanto à questão de classificação do aluno PAEE, é importante considerar que é possível a realização de adaptações curriculares, a partir da observância das habilidades dos alunos, contudo, sem dúvida, a grande preocupação é com o processo de ensino e aprendizagem dos discentes e com o desenvolvimento de suas funções psíquicas superiores.

Siqueira e Santana (2010, p.135) concluíram que o novo milênio inaugura “[...] a era da diversidade na qual não cabe mais discriminar e excluir, pois o reconhecimento e a inclusão de pessoas deficientes representam um avanço significativo para a instauração de uma sociedade plenamente democrática”.

Compartilhamos com o pensamento de Saviani (2005), ao entendermos, tal como o autor, que a escola possui um papel importante para que uma sociedade seja democrática, e esse papel está em sua responsabilidade no ensino, a fim de que o aluno se aproprie do conhecimento e da cultura historicamente produzidos. Essa é uma das razões para que a escola deixe seu caráter assistencialista ou conservador e que se volte para o seu principal papel, o de ensinar.

É importante considerar que o ideário do aprender a aprender, oponente às questões do ensinar, defendidas por Saviani (2005) e Duarte (2013), com um propósito específico e deliberado de

[...] imprimir ao capitalismo as marcas da fluidez e da volatilidade necessárias à sua reprodução, pois a qualquer hora pode-se inverter completamente o caminho assumido e se reclamar a necessidade de outros saberes e fazeres que sejam mais convenientes a dado contexto histórico. (BEZERRA; ARAUJO, 2013, p.579).

Assim, entendemos que Bezerra e Araujo (2013) contribuem com o avanço dos estudos da temática, ao se posicionam criticamente sobre como situa-se a acessibilidade ao Ensino Superior dos discentes PAEE, com destaque às ações que buscam a aquisição de produtos e tecnologias; com atitudes sociais; visando às políticas de inclusão. É importante considerar a acessibilidade do discente, desde seu ingresso no Ensino Superior, com garantias para a sua permanência com um ensino de qualidade. Que o 
discente PAEE aprenda a partir de suas habilidades e potencialidades, possibilitando-lhe condições efetivas de trabalho como egresso do ensino superior.

Tabela 1 - Revista Brasileira de Educação Especial - 2010

\begin{tabular}{l|l|l}
\multicolumn{1}{c|}{ Autores } & \multicolumn{1}{|c}{ Título } & \multicolumn{1}{c}{ Palavras-chave } \\
\hline $\begin{array}{l}\text { Inajara Mills Siqueira; } \\
\text { Carla da Silva Santana. }\end{array}$ & $\begin{array}{l}\text { Propostas de acessibilidade para a } \\
\text { inclusão de pessoas com } \\
\text { deficiências no ensino superior. }\end{array}$ & $\begin{array}{l}\text { Inclusão educacional. Educação das } \\
\text { pessoas com deficiência. Condições de } \\
\text { acesso e permanência na escola. }\end{array}$ \\
\hline
\end{tabular}

Fonte: SciELO (s.d.).

Em 2011, dos 36 artigos publicados como Relatos de Pesquisas e em Edição Especial com o Tema ANPEd, dois artigos trataram do nível Ensino Superior associado ao tema Educação Especial, conforme Tabela 2. O artigo de Lacerda e Gurgel (2011), "Perfil de tradutores-intérpretes de Libras (TILS) que atuam no ensino superior no Brasil", apresenta contribuições aos tradutores-intérpretes do Ensino Superior que trabalham com alunos surdos. As autoras apresentam o perfil desses tradutoresintérpretes de Libras no Brasil. Esse perfil, conforme demonstrado pelas estudiosas, pode colaborar com os profissionais da área, desmistificando conceitos e apoiando uns aos outros na trajetória de trabalho com surdos no Ensino Superior.

Dentre as contribuições do estudo apresentado por Lacerda e Gurgel (2011) é interessante destacar a conclusão do artigo, oportunamente afirmam a relevância de se conhecer as diferentes realidades do Brasil, pensando na formação de intérpretes educacionais, além de considerarem que isso as possibilitaram “[...] visualizar a área em constituição e [os resultados] apontam para características que podem ser consideradas nas reflexões e projetos que se interessam pelas necessidades formativas de TILS". (LACERDA; GURGEL, 2011, p.495).

O artigo "A formação do professor olhada no/pelo GT-15 - educação especial da ANPEd: desvelando pistas” de Jesus, Barreto e Gonçalves (2011), busca “[...] apresentar uma metanálise sobre a produção na área de formação de professor e Educação Especial", com muito cuidado na análise dos 14 textos organizados em quatro eixos temáticos: “[...] análise do estado da arte na área; formação inicial; formação continuada e avaliação de programas de formação do período de 2000 a 2010”. (JESUS; BARRETO; GONÇALVES, 2011, p.79).

Essas autoras trazem para a discussão importantes artigos apresentados na ANPEd acerca da formação de professores, com análises relevantes sobre o contexto em 
que ocorreu a formação docente, assim como com o enfoque que foi dado às pesquisas, no limiar do século XXI. Finalizam o artigo convidando os leitores para a continuação do diálogo em eventos e grupos de pesquisas, considerando a abertura para outras e novas contribuições e sinalizam que: “[...] para além, se coloca a responsabilização de grupos de pesquisa da área para buscar aprofundamento teórico e metodológico, bem como outras tensões a serem investigadas”. (JESUS; BARRETO; GONÇALVES, 2011, p.90).

Pensamos ainda em complementar esse convite das autoras, com a reflexão de Bezerra e Araujo (2013, p.578) destacando que “[...] as reflexões ora expostas talvez venham suscitar outras pesquisas e ampliar os debates sobre a educação escolar inclusiva, no interesse da formação docente e da emancipação genérica do homem com ou sem deficiência”. Desta forma, busca-se preencher lacunas nessa área que cresce continuamente com o ingresso do PAEE no Ensino Superior e com a legislação em todas as esferas, municipal, estadual e federal, que garante o direito desses alunos PAEE estudarem em todos os níveis de ensino e em todos os tipos de instituições públicas e privadas.

Tabela 2 - Revista Brasileira de Educação Especial - 2011

\begin{tabular}{l|l|l}
\hline \multicolumn{1}{c|}{ Autores } & \multicolumn{1}{c|}{ Título } & \multicolumn{1}{c}{ Palavras-chave } \\
\hline $\begin{array}{l}\text { Cristina Broglia Feitosa de } \\
\text { Lacerda; Taís Margutti do } \\
\text { Amaral Gurgel. }\end{array}$ & $\begin{array}{l}\text { Perfil de tradutores-intérpretes de } \\
\text { Libras (TILS) que atuam no ensino } \\
\text { superior no Brasil. }\end{array}$ & $\begin{array}{l}\text { Educação Especial. Tradutor Intérprete } \\
\text { de LIBRAS. Ensino Superior. Inclusão } \\
\text { Bilíngue. }\end{array}$ \\
\hline $\begin{array}{l}\text { Denise M. de Jesus; Maria } \\
\begin{array}{l}\text { A. S. Corrêa Barreto; Agda } \\
\text { F. S. Gonçalves. }\end{array}\end{array}$ & $\begin{array}{l}\text { A formação do professor olhada } \\
\text { no/pelo GT-15 - educação especial } \\
\text { da ANPED: desvelando pistas. }\end{array}$ & $\begin{array}{l}\text { Formação de Professor. Educação } \\
\text { Especial. Inclusão Escolar. ANPEd. }\end{array}$ \\
\hline
\end{tabular}

\section{Fonte: SciELO (s.d.).}

Em 2012, dos 36 artigos publicados, um tratou do tema Ensino Superior, conforme Tabela 3. Rodrigues e Capellini (2012, p.619), pesquisaram sobre a Formação continuada docente com a utilização da Educação à Distância. O objetivo da pesquisa foi o de “[...] levantar e analisar dados em relação à sua utilização para formação continuada de professores quanto ao processo de inclusão da pessoa com deficiência". As autoras afirmaram que a Educação a Distância é uma ótima contribuição para o trabalho com a formação continuada, por atender necessidades emergenciais dos professores sobre a Educação Especial. Ressaltam que: “[...] é importante destacar que 
ainda há práticas dessa modalidade que levantam questionamento em relação à qualidade dos cursos ofertados, como por exemplo, cursos que não apresentam metodologia adequada e não conduzem o aluno para a efetiva aprendizagem". (RODRIGUES; CAPELLINI, 2012, p.625).

Rodrigues e Capellini (2012, p.626) defendem a educação a distância, fazendo considerações sobre sua relevância, inclusive afirmam que o funcionamento dos cursos de formação continuada de professores depende de como são assistidos e do comprometimento desses profissionais, "[...] para isso, é importante estruturar um curso em que os participantes tenham a sensação de estar sendo assistidos em todos os momentos, e que sempre poderão contar com o formador e/ou tutor".

Quanto à assistência aos alunos da Educação a Distância há críticas, principalmente no que se refere a despertar o interesse do aluno para a realização das atividades propostas, e para assistir ao curso, validando assim, o conhecimento adquirido e o certificado. Para Rodrigues e Capellini (2012) é importante que as pessoas rompam com conceitos equivocados sobre o ensino a distância não possibilitar aprendizagem, pois “[...] o sucesso do curso dependerá, entre outros aspectos, da interlocução entre os participantes, da troca de experiências entre colegas e professor, utilizando o ambiente para comunicação e criação da comunidade virtual, que, ao mesmo tempo, aprende e ensina" (RODRIGUES; CAPELLINI, 2012, p.626). Muitos debates podem suscitar desse tema, principalmente associando a formação docente ao trabalho com alunos PAEE, pois o assunto confronta muitas tendências pedagógicas.

Tabela 3 - Revista Brasileira de Educação Especial - 2012

\begin{tabular}{c|c|c}
\multicolumn{1}{c|}{ Autores } & \multicolumn{1}{c|}{ Título } & \multicolumn{1}{c}{ Palavras-chave } \\
\hline $\begin{array}{l}\text { Leda M. B. C. Rodrigues; } \\
\text { Vera L. M. F. Capellini. }\end{array}$ & $\begin{array}{l}\text { Educação a distância e formação } \\
\text { continuada do professor. }\end{array}$ & $\begin{array}{l}\text { Educação especial. Educação à distância. } \\
\text { Formação de professores. Inclusão. }\end{array}$ \\
\hline
\end{tabular}

Fonte: SciELO (s.d.).

Em 2013, três artigos trataram do tema Ensino Superior, considerando um cômputo de 27 artigos, conforme Tabela 4. Desses, o artigo "Objetos de aprendizagem como recurso pedagógico em contextos inclusivos: subsídios para a formação de professores a distância" consideramos complementar ao artigo da Tabela 3, ao trazer uma discussão sobre a formação de professores a distância, como formação continuada 
de professores e este trata da formação inicial, o que provoca críticas sobre suas possibilidades de atendimento, bem como a qualidade do ensino, tornando um tema polêmico e contraditório no meio educacional.

Os discentes PAEE sofrem com qualidade do ensino, assim como os estudantes da classe trabalhadora, ou seja, a existência de um jogo político e ideológico com o objetivo de "[...] assegurar que os conteúdos ensinados e aprendidos na escola pública se limitem ao que é demandado pela reprodução da divisão social do trabalho e da concepção burguesa de sociedade, de conhecimento, de vida humana e de individualidade". (DUARTE, 2013, p.27).

Ampliando a discussão sobre formação docente apresentamos o artigo "Formação de professores para a educação especial: uma discussão sobre os modelos brasileiro e italiano" que nos possibilita conhecer, de forma comparativa, essas duas realidades. À guisa de conclusão, Greguol, Gobbi e Carraro (2013, p.321) afirmam que:

Tanto Brasil como Itália ainda têm pela frente grandes desafios a serem superados para garantir a inclusão escolar com qualidade e a formação docente, que em nosso país ainda carece de diretrizes mais específicas, certamente é um pilar fundamental dentro desta premissa. Porém, é preciso destacar que não é a simples replicação de modelos adotados em outros países que trará os frutos esperados, já que existem diversas particularidades geográficas e culturais que precisam ser observadas.

Duarte et al. (2013), autores do artigo "Estudo de caso sobre a inclusão de alunos com deficiência no Ensino Superior", apresentam um estudo realizado em Juiz de Fora-MG, onde há dez IES privadas e uma pública. Os autores constataram que a rede privada representa $82,2 \%$ desse total e a rede pública federal, $17,8 \%$, ou seja, dos 45 estudantes, 37 estão nas IES privadas e oito na IES Pública, uma boa média entre a IES pública (01) e o quantitativo de IES privadas que os discentes PAEE estão matriculados (08). Nesse artigo, chama atenção a conclusão dos autores que destacam a necessidade se realizar outras pesquisas na área, o que é reforçado por Duarte (2013, p.297) ao afirmar que essas pesquisas precisam acompanhar “"[...] o processo de consolidação da proposta de acesso e permanência no Ensino Superior das pessoas com deficiência", ou seja, os autores percebem a necessidade de pesquisas em outras localidades públicas e privadas que têm discentes PAEE matriculados. 
Tabela 4 - Revista Brasileira de Educação Especial - 2013

\begin{tabular}{|c|c|c|}
\hline Autores & Título & Palavras-chave \\
\hline $\begin{array}{l}\text { Lívia Raposo Bardy; Maria } \\
\text { Cristina P. I. Hayashi; } \\
\text { Elisa T. M. Schlünzen; } \\
\text { Manoel Osmar S. Júnior. }\end{array}$ & $\begin{array}{l}\text { Objetos de aprendizagem como } \\
\text { recurso pedagógico em contextos } \\
\text { inclusivos: subsídios para a formação } \\
\text { de professores a distância. }\end{array}$ & $\begin{array}{l}\text { Educação Especial. Tecnologia da } \\
\text { informação e da comunicação. } \\
\text { Inclusão educacional. }\end{array}$ \\
\hline $\begin{array}{l}\text { Emerson R. Duarte; Carla } \\
\text { B. S. Rafael; Juliana F. } \\
\text { Filgueiras; Clara } \\
\text { Neves; Maria } \\
\text { Ferreira. }\end{array}$ & $\begin{array}{l}\text { Estudo de Caso Sobre a Inclusão de } \\
\text { Alunos com Deficiência no Ensino } \\
\text { Superior. }\end{array}$ & $\begin{array}{l}\text { Educação Especial. Pessoa com } \\
\text { Deficiência. Ensino Superior. }\end{array}$ \\
\hline $\begin{array}{l}\text { Márcia Greguol; Erica } \\
\text { Gobbi; Attilio Carraro. }\end{array}$ & $\begin{array}{l}\text { Formação de professores para a educ. } \\
\text { especial: uma discussão sobre os } \\
\text { modelos brasileiro e italiano. }\end{array}$ & $\begin{array}{l}\text { Educação Especial. Formação de } \\
\text { Professores. Inclusão. }\end{array}$ \\
\hline
\end{tabular}

Fonte: SciELO (s.d.).

Não mencionaremos cada artigo da Tabela 5, porém os interessados pelo tema devem fazer sua leitura, considerando serem os atuais, e como regra de aproximação, são os últimos publicados pela revista. Assim, em 2014, cinco artigos trataram do tema Ensino Superior associado ao tema Educação Especial, conforme Tabela 5, em um total de 34 relatos de pesquisas. Desses cinco artigos, dois têm como objeto de estudo as altas habilidades ou superdotação, dois discutem formação docente e um a acessibilidade e permanência do aluno com deficiência no Ensino Superior.

Os artigos apresentados na Tabela 5 possibilitam um olhar para as especificidades de uma clientela que está chegando ao Ensino Superior e, para garantir sua permanência são necessários trabalhos que envolvam a descoberta de suas habilidades e potencialidades, que contem com adaptações curriculares, com conhecimentos sobre mediação e compensação, para assim garantir um ensino de qualidade para cada um, que propiciará aprendizagem e desenvolvimento, pois “A ressignificação da educação especial trouxe, de fato, algumas possibilidades humanizadoras para se repensar o desenvolvimento dos alunos com e sem deficiência em uma mesma sala de aula, sem exceções”. (BEZERRA; ARAUJO, 2013, p.581). 
Tabela 5 - Revista Brasileira de Educação Especial - 2014

\begin{tabular}{|c|c|c|}
\hline Autores & Título & Palavras-chave \\
\hline $\begin{array}{lll}\text { Sabrina } & \text { Fernandes de } \\
\text { Castro; } & \text { Maria } & \text { Amelia } \\
\text { Almeida. } & & \end{array}$ & $\begin{array}{l}\text { Ingresso e Permanência de Alunos } \\
\text { com Deficiência em Universidades } \\
\text { Públicas Brasileiras. }\end{array}$ & $\begin{array}{l}\text { Educação Especial. Alunos com } \\
\text { Deficiência. Ensino Superior. Ingresso e } \\
\text { Permanência. }\end{array}$ \\
\hline $\begin{array}{l}\text { Cláudia A. Bisol; Carla } \\
\text { Beatris Valentini. }\end{array}$ & $\begin{array}{l}\text { Objeto Virtual de Aprendizagem } \\
\text { Incluir: Recurso para a Formação } \\
\text { de Professores Visando à Inclusão. }\end{array}$ & $\begin{array}{l}\text { Educação Especial. Inclusão } \\
\text { Educacional. Formação de Professores. } \\
\text { Tecn. Educacional. }\end{array}$ \\
\hline $\begin{array}{l}\text { Jairo V. de A. Ramalho; } \\
\text { Denise N. Silveira; Willian } \\
\text { S. Barros; Ruth da S. } \\
\text { Brum. }\end{array}$ & $\begin{array}{l}\text { A Carência de Formação Sobre a } \\
\text { Superdotação nas Licenciaturas da } \\
\text { UFPEL: um Estudo de Caso. }\end{array}$ & $\begin{array}{l}\text { Educação } \quad \text { Especial. } \\
\text { Habilidades/Superdotação. Matemática. } \\
\text { Mitos. Talento. }\end{array}$ \\
\hline $\begin{array}{l}\text { Andréa Regina Rosin- } \\
\text { Pinola; Zilda Aparecida } \\
\text { Pereira Del Prette. }\end{array}$ & $\begin{array}{l}\text { Inclusão Escolar, Formação de } \\
\text { Professores e a Assessoria Baseada } \\
\text { em Habilidades Sociais Educativas. }\end{array}$ & $\begin{array}{l}\text { Educação Especial. Inclusão Escolar. } \\
\text { Formação de Professores. Habilidades } \\
\text { Sociais. }\end{array}$ \\
\hline $\begin{array}{l}\text { Fabiane S. Chueire Cianca; } \\
\text { Maria } \\
\text { Marquezine. }\end{array}$ & $\begin{array}{l}\text { A Percepção dos Coordenadores de } \\
\text { Licenciaturas da UEL sobre Altas } \\
\text { Habilidades/Superdotação }\end{array}$ & $\begin{array}{lr}\text { Educação } \quad \text { Especial. } & \text { Altas } \\
\text { habilidades/superdotação. } & \text { Ensino } \\
\text { superior. Curso de licenciatura. } & \end{array}$ \\
\hline
\end{tabular}

Fonte: SciELO (s.d.).

Os artigos mapeados na RBEE evidenciam que a chegada de discentes PAEE no Ensino Superior começa a ser olhada com maior frequência, conforme as publicações da RBEE, que são um termômetro para indicar esses dados. Em 2010, apenas um artigo foi publicado sobre o tema, já em 2014 foram cinco artigos. A análise não leva em consideração apenas os dados quantitativos, mas também o interesse dos pesquisadores pelo tema, o que demonstra a necessidade de novas posturas nas estruturas arraigadas da Educação.

\section{Considerações finais}

[...] conclamar as pessoas a acabarem com as ilusões acerca de uma situação é conclamá-las a acabarem com uma situação que precisa de ilusões. (MARX apud DUARTE, 2001, p.9).

A contribuição de Marx (apud DUARTE, 2001, p.9), constante nessa epígrafe facilita fechar este texto momentaneamente, da mesma forma possibilita abri-lo para discussões que poderão envolver pesquisadores iniciantes e experientes, pois a incerteza, a dúvida, a não verdade absoluta é que facilitam o diálogo, neste caso, em 
especial, sobre a Educação Especial no Ensino Superior. Diálogo que busca na reflexão afirmar que as contribuições dos autores dos artigos da RBEE sobre Educação Especial no Ensino Superior, no período de 2010 a 2014, condizem parcialmente com as necessidades do PAEE, pois em alguns artigos, não ocorreram avanços significativos na discussão, principalmente no que se refere à formação docente para alunos que atuarão na Educação Básica.

Quanto aos temas publicados nos artigos em análise, não há uma prevalência a um tipo de PAEE. O que verificamos é que em 2014 aparecem dois artigos sobre altas habilidades ou superdotação, os outros discutem questões gerais sobre formação docente, acessibilidade, educação a distância, tecnologia, enfim, são tratados a partir de diferentes públicos da Educação Especial “incluídos” no Ensino Superior. Outro ponto que observamos é que os artigos discutiram tenuemente sobre a práxis docente e quando o fizeram, não se alicerçaram a uma base teórica consistente, ou seja, as análises não avançaram em relação ao que já vem sendo publicado e debatido em eventos científicos da área.

Em síntese, com base nos artigos analisados, concluímos que os discentes com deficiência que chegam ao Ensino Superior enfrentam dificuldades várias, relativas ao preconceito velado, acessibilidade física, inadequação curricular, invisibilidade, dentre outras dificuldades. A inclusão de alunos PAEE requer atenção, desde a Educação Infantil. Há necessidade com trabalhos educacionais concretos, que não negligenciem o desenvolvimento de suas funções psíquicas superiores ou de compensação social, por meio da mediação por signos, para que consigam transpor barreiras existentes em todos os níveis escolares. Somente uma educação relevante, pertinente e compatível com o cunho da Educação Especial, contribuirá para uma educação emancipadora dos PAEE.

\section{SPECIAL EDUCATION IN HIGHER EDUCATION: CONTRIBUTIONS AND PERSPECTIVES}


Abstract: With the advent of special education in Brazil boosted by the Salamanca Declaration (1994), some theoretical positions presented themselves, such as the full inclusion of persons with disabilities in ordinary schools and the inclusion from the look from the perspective of the development of higher psychological functions (VYGOTSKY, 1997). In addition, there are other theoretical positions and intermediate educational practices aimed at organic conditions of students with disabilities and to the possibilities of integration of those more committed in relation to disability in specialized education centers. From these considerations is that aims to understand the contributions of the authors of 12 articles of the Brazilian Journal of Special Education (RBEE) on special education in higher education, as well as the prospects for the students of special education target audience (PAEE) that enters the higher education. The qualitative approach, from the perspective of Cultural-historical. Psychology, has guided the analysis of these RBEE productions, in the period from 2010 to 2014. As a result it was found that the students who reach the PAEE higher education face difficulties through veiled prejudice, physical accessibility, inadequate curriculum, among others. It can be concluded that the inclusion of students PAEE lacks attention, since Kindergarten, with educational work guided in developing their higher psychological functions, so you can overcome the barriers located at all levels of schooling, so as to contribute to not only reach to higher education, but also (and especially) that come out with knowledge.

Key words: Special education. Higher education. Intellectual production. CulturalHistorical Psychology.

\section{REFERÊNCIAS}

BEZERRA, G. F.; ARAUJO, D. A. C. Em busca da flor viva: para uma crítica ao ideário inclusivista em educação. Educação \& Sociedade, Campinas, v.34, n.123, p.573-588, 2013.

DUARTE, E. R. Vigotski e a pedagogia histórico-crítica: a questão do desenvolvimento psíquico. Nuances: estudos sobre Educação, Presidente Prudente, v.24, n.1, p.19-29, 2013.

Vigotski e o "Aprender a Aprender": crítica às apropriações neoliberais e pós-modernas da teoria Vigotskiana. 2.ed. Campinas: Autores Associados, 2001.

et al. Estudo de caso sobre a inclusão de alunos com deficiência no ensino superior. Revista Brasileira de Educação Especial, Marília, v.19, n.2, p.289-300, abr./jun. 2013.

GREGUOL, M.; GOBBI, E.; CARRARO, A. Formação de professores para a educação especial: uma discussão sobre os modelos brasileiro e italiano. Revista Brasileira de Educação Especial, Marília, v.19, n.3, p.307-324, jul./set. 2013.

JESUS, D. M.; BARRETO, M. A. S. C.; GONÇALVES, A. F. S. A formação do professor olhada no/pelo GT-15 - educação especial da ANPED: desvelando pistas. Revista Brasileira de Educação Especial, Marília, v.17, p.77-92, mai./ago. 2011. 
LACERDA, C. B. F.; GURGEL, T. M. A. Perfil de tradutores-intérpretes de Libras (TILS) que atuam no ensino superior no Brasil. Revista Brasileira de Educação Especial, Marília, v.17, n.3, p.481-496, set./dez. 2011.

RODRIGUES, L. M. B. C.; CAPELLINI, V. L. M. F. Educação a distância e formação continuada do professor. Revista Brasileira de Educação Especial, Marília, v.18, n.4, p.615-628, out./Dez. 2012.

SAVIANI, D. Pedagogia histórico-crítica: primeiras aproximações. 9.ed. Campinas: Autores Associados, 2005.

SciELO. Revista Brasileira de Educação Especial. [Online]. Disponível em: $<$ http://www.scielo.br/scielo.php?script=sci_issues\&pid=14136538\&lng=pt\&nrm=iso >. Acessado em: 02 jun. 2015.

SIQUEIRA, I. M.; SANTANA, C. S. Propostas de acessibilidade para a inclusão de pessoas com deficiências no ensino superior. Revista Brasileira de Educação Especial, Marília v.16, n.1, p.127-136, jan./abr. 2010.

VYGOTSKI, L. S. Fundamentos da defectología V. Madrid: Aprendizaje Visor, 1997. 